\title{
Beta-blocker therapy in patients with left ventricular systolic dysfunction and chronic obstructive lung disease in an ambulatory care setting
}

\author{
Jennifer J. SCHIMMER, Sarah J. BILLUPS, Thomas DELATE.
}

Received (first version): 18-Jun-2009 Accepted: 9-Nov-2009

\begin{abstract}
${ }^{*}$
Objective: To evaluate beta blocker persistence six months after beta-blocker initiation or dose titration in heart failure (HF) patients with COPD compared to those without COPD. Secondary objectives included comparison of beta-blocker dose achieved, changes in left ventricular ejection fraction (LVEF) and incidence of hospitalizations or emergency department (ED) visits during follow-up.

Methods: We conducted a matched, retrospective, cohort study including 86 patients with COPD plus concomitant HF (LVEF $\leq 40 \%$ ) and 137 patients with $\mathrm{HF}$ alone. All patients were followed in an outpatient HF clinic. Eligible patients had a documented LVEF $\leq 40 \%$ and were initiated or titrated on a betablocker in the HF clinic. Patients were matched based on LVEF (categorized as $\leq 20 \%$ or $21-40 \%$ ), gender, and age ( $>$ or $\leq 70$ years). The primary outcome was beta blocker persistence at 6 months. Secondary outcomes were dose achieved, LVEF, and incidence of hospitalizations or ED visits. Results: There were no differences between the COPD and non-COPD groups in beta-blocker persistence at six-month follow-up $(94.2 \%$ vs. $93.4 \%$ respectively, adjusted $\mathrm{p}=0.842$ ). The proportion of patients who achieved a daily metoprolol dose equivalent of at least $100 \mathrm{mg}$ was similar between the groups (adjusted $p=0.188$ ). The percent of patients with at least one ED visit or hospitalization in the six-month post-titration period was substantial but similar between the groups (53.5\% and $48.2 \%$ for COPD and non-COPD patients, respectively, adjusted $p=0.169$ ). Conclusion: Our results support the use of betablockers in the population of heart failure patients with COPD and without reactive airway disease.
\end{abstract}

Keywords: Adrenergic beta-Antagonists. Heart Failure. Pulmonary Disease, Chronic Obstructive. United States.

\footnotetext{
Jennifer J. SCHIMMER. PharmD, BCPS. Clinical Pharmacy Specialist in Cardiology, Kaiser Permanente Colorado; Clinical Instructor, University of Colorado Denver School of Pharmacy. Denver, CO (United States). Sarah J. BILLUPS, PharmD, BCPS. Clinical Pharmacy Specialist in Research, Kaiser Permanente Colorado; Clinical Assistant Professor, University of Colorado Denver School of Pharmacy. Denver, CO (United States). Thomas DELATE, PhD, MS. Clinical Pharmacy Research Scientist, Kaiser Permanente Colorado; Clinical Instructor, University of Colorado Denver School of Pharmacy. Denver, CO (United States).
}

\author{
TRATAMIENTO CON BETABLOQUEANTES \\ EN PACIENTES CON DISFUNCIÓN \\ SISTÓLICA VENTRICULAR IZQUIERDA Y \\ ENFERMEDAD PULMONAR \\ OBSTRUCTIVA CRÓNICA EN MEDIO \\ AMBULATORIO
}

\section{RESUMEN}

Objetivo: Evaluar la persistencia de los beta bloqueantes seis meses después de su iniciación o ajuste de dosis en pacientes con fallo cardíaco (FC) con EPOC comparados con los que no tienen EPOC. Los objetivos secundarios incluían la comparación de la dosis de beta bloqueante alcanzada, los cambios en la facción eyectada ventricular izquierda (FEVI) y la incidencia de hospitalizaciones y visitas a urgencias durante el periodo de seguimiento.

Métodos: Condujimos un estudio de cohorte emparejada, retrospectivo que incluyó a 86 pacientes con EPOC concomitante de FC $(\mathrm{FEVI} \leq 40 \%))$ y 137 pacientes con sólo FC. Todos los pacientes fueron seguidos en una clínica ambulatoria de FC. Los pacientes elegibles tenían una $\mathrm{FEVI} \leq 40 \%$ y habían iniciado o ajustado los beta bloqueantes en la clínica de FC. Los pacientes se emparejaron en función de la FEVI (categorizados como $\leq 20 \%$ o $21-40 \%$ ), género y edad ( $>$ or $\leq 70$ años). El resultado primario era la persistencia del beta bloqueante a los 6 meses. Los resultados secundarios eran la dosis alcanzada, la FEVI y la incidencia de hospitalizaciones o visitas a urgencias.

Resultados: No hubo diferencias entre los grupos de pacientes con EPOC y sin EPOC en la persistencia de beta bloqueantes a los seis meses de seguimiento (94.2\% vs. 93.4\% respectivamente, ajustado $\mathrm{p}=0.842$ ). La proporción de pacientes que alcanzaron una dosis equivalente de metoprolol de al menos $100 \mathrm{mg}$ fue similar entre los grupos (adjusted $\mathrm{p}=0.188$ ). El porcentaje de pacientes con al menos una visita $u$ hospitalización en los seis meses después del periodo de ajuste fue sustancial pero similar entre los dos grupos (53.5\% y 48.2\% para pacientes EPOC y no-EPOC, respectivamente, ajustado $\mathrm{p}=0.169$ ).

Conclusión: Nuestros resultados apoyan el uso de beta bloqueantes en la población de pacientes con fallo cardiaco con EPOC y sin enfermedad aérea reactiva. 
Palabras clave: Antagonistas beta-adrenérgicos. Fallo cardiaco. Enfermedad pulmonar obstructiva crónica. Estados Unidos.

\section{INTRODUCTION}

Current American College of Cardiology/American Heart Association (ACC/AHA) guidelines and Heart Failure Society of America guidelines for management of chronic heart failure (HF) recommend angiotensin converting enzyme (ACE) inhibitors, beta-blockers, and aldosterone antagonists for those patients with persistent ejection fraction $<35-40 \%$ and Stage $C$ or D heart failure. ${ }^{1,2}$ Randomized, placebo-controlled clinical trials with all three classes of these medications have shown substantial reductions in morbidity and mortality in HF patients. ${ }^{1-6}$

Although beta-blockers have been shown to significantly reduce mortality, improve myocardial contractility, and reverse cardiac dilation in HF patients, they are not consistently used in HF patients with concomitant chronic obstructive pulmonary disease (COPD). ${ }^{7-9}$ Estimates of the prevalence of COPD in patients with known chronic HF range from $23 \%$ to $39 \%$. ${ }^{10-11}$ Beta-blockers antagonize beta-2 receptors in lung airways, inhibiting bronchodilation and potentially causing bronchoconstriction. Initial clinical trials evaluating beta-blocker use in HF excluded patients with any lung disease, including COPD. ${ }^{8-11}$ One study in patients with irreversible lung disease reported negative effects on lung function, but the investigators initiated beta-blockers at target or near-target doses without a titration period. ${ }^{12}$ Based on this knowledge, healthcare providers may hesitate to prescribe beta-blockers in HF patients with COPD for fear of exacerbating their lung disease. ${ }^{7-15}$ Although there is limited data on the rate of beta-blocker prescribing in this population, one study reported only 18 out of $56(32 \%)$ patients identified as having COPD and HF were currently prescribed a beta-blocker. ${ }^{7}$ A more recent retrospective cohort study reported beta-blocker prescribing rates to be similar in COPD patients compared to non-COPD HF patients $(86.3 \%$ vs. $87.6 \%$ respectively). ${ }^{16}$ Neither study compared the characteristics of the COPD patients prescribed a beta-blocker to those that were not. Cardioselective beta-blockers, such as atenolol, metoprolol and bisoprolol act primarily on beta-1 receptors, although this selectivity wanes at higher doses. ${ }^{8,9}$ Non-selective beta-blockers such as carvedilol inhibit beta-2 receptors at all doses. ${ }^{8-10}$

A recent meta-analysis evaluated the effect of cardioselective beta-blockers on patients with lung disease, including COPD, with therapy ranging from 2 days to 12 weeks. ${ }^{17}$ The authors concluded that cardioselective beta-blockers, given as a single dose or for longer durations, produced no change in lung function. ${ }^{17}$
Three studies have reported on the use of betablockers in HF patients with concomitant COPD. In a prospective study, the majority $(84 \%)$ of $\mathrm{HF}$ patients with COPD $(n=31)$ tolerated carvedilol for at least six months without reducing their spirometry-determined lung function. ${ }^{18}$ These authors also reported improvements in left ventricular end-diastolic diameter, left ventricular end-systolic diameter, and fractional shortening in patients that remained on carvedilol at follow-up. ${ }^{18}$ However, the small sample size, open-label design, and inpatient setting limit this study's application. In a retrospective study, 124 patients with HF and COPD were initiated on a beta-blocker (bisoprolol, atenolol, or carvedilol). A large majority (84\%) continued to take the beta-blocker after one-year without a reduction in spirometry-determined lung function. ${ }^{14}$ However, these investigators did not evaluate cardiac function, hospitalizations, or emergency department (ED) visits after betablocker initiation. Another retrospective evaluation reported no difference in beta-blocker prescribing or incidence of death or hospitalization after betablocker initiation between ambulatory HF patients with $(n=73)$ and without $(n=113)$ COPD. $^{16}$ Unfortunately, this study did not evaluate changes in cardiac function after initiation.

Due to the paucity of comprehensive information regarding the clinical outcomes of the use of betablocker therapy in HF patients with COPD, this investigation was undertaken to assess betablocker persistence, cardiac function, and healthcare utilization after beta-blocker initiation. These outcomes were compared between HF patients with and without COPD who were initiated on beta-blocker therapy in a multidisciplinary outpatient HF clinic. The information derived from this study may assist healthcare providers in their deliberations over the use of beta-blocker therapy in HF patients with COPD.

\section{METHODS}

\section{Setting}

This study was conducted at Kaiser Permanente Colorado (KPCO), a group model health maintenance organization that provides non-profit healthcare services to over 470,000 members at 18 medical offices in the Denver-Boulder metropolitan area. The KPCO Heart Failure Clinic was established on September 10, 2001 for the purpose of initiating, monitoring, and overall management of the medications of patients with a left ventricular ejection fraction (LVEF) $\leq 40 \%$. Medications utilized in this population include vasodilators (angiotensinconverting enzyme inhibitors, angiotensin II receptor blockers, or hydralazine and nitrates), betablockers, spironolactone, diuretics, and digoxin when appropriate. The clinic is staffed on a rotating basis by 8 cardiologists, 4 registered nurses, and a clinical pharmacy specialist. Patients are monitored closely in clinic and by telephone to assess tolerance and adherence to medications. At the time of this study, the beta-blockers utilized in this clinic included metroprolol tartrate, atenolol, and carvedilol (see Table 2). This study was reviewed 
and approved by the KPCO Institutional Review Board.

\section{Study Design}

This was a matched, retrospective cohort analysis. Patient outcomes were assessed six months after completion of beta-blocker titration to target or maximum tolerated dose (completion of HF clinic enrollment). Information on patient eligibility, characteristics, and study outcomes were obtained from manual review of eligible patients' electronic medical records. Medical claims were examined for diagnoses recorded during ED visits and inpatient hospitalizations that occurred during or following beta-blocker titration. Cases were HF patients with a physician-confirmed COPD diagnosis. Potential control HF patients were matched to cases up to 2:1 according to LVEF (categorized as $<$ or $=20 \%$ \& $21-40 \%)$, gender, and age ( $>\&<$ or $=70$ years).

\section{Study Population}

All adult KPCO members enrolled in the KPCO Heart Failure clinic were assessed for eligibility via chart review. Inclusion criteria were: (1) a LVEF $<40 \%$; (2) initiated or titrated on a beta-blocker in the HF clinic between September 10, 2001 and September 1, 2003; and (3) at least two documented visits to the HF clinic. Heart failure patients with potential COPD were excluded if (1) the diagnosis was not confirmed by spirometry or a physician or (2) the patient had only a reactive component to his or her lung disease according to pulmonary function testing. At the time of enrollment in the HF clinic, patients began titration to a target metoprolol equivalent dose of $200 \mathrm{mg}$ or their maximum tolerated dose.

\section{Outcomes}

The primary outcome was beta-blocker persistence six months after beta-blocker initiation or dose titration (HF clinic enrollment). Persistence and not adherence was utilized as the primary outcome since persistence is a more robust indicator of therapy continuation. Accurate assessment of adherence was precluded by the small and variable doses used during dose titration. Persistence was defined by identifying the medication fill most proximal to the 6 -month follow-up date $(=6$ months after completion of dose-titration and discharge from HF clinic) and determining if that fill provided an adequate days supply of medication to carry through to that date. Secondary outcomes included highest beta-blocker dose achieved, changes in LVEF from HF clinic enrollment (baseline) to the end of the follow-up period, and percent of patients with at least one hospitalization stay or ED visit during the follow-up period. In addition, COPDrelated therapies and reasons for beta-blocker discontinuation, where applicable, were tabulated.

Analysis

Based upon an anticipated $90 \%$ beta-blocker persistence rate in the COPD group, an absolute difference of $11 \%$ in the rates could be detected in this patient population with $80 \%$ power. Characteristics abstracted during medical record review included patient age, New York Heart Association (NYHA) classification, LVEF, COPD severity, and COPD-related therapies (where applicable) at the time of HF clinic enrollment. Additionally, information on gender, HF etiology, presence of diabetes and/or hypertension, betablocker initiated, and presence of an inpatient hospitalization or ED visit during the six months prior to HF clinic enrollment were collected. The LVEFs were determined by echocardiography, left ventriculography, stress test, or multiple gated acquisition scan or MUGA. In addition, beta-blocker persistence, dose, and presence of a hospitalization or ED visit during the six-month follow-up were recorded. Baseline COPD severity was categorized as mild, moderate, severe, or very severe based upon pulmonary function testing, when available, and according to COPD GOLD Guidelines. ${ }^{19}$ Follow-up LVEFs were obtained by echocardiography between six and twelve months after completion of beta-blocker titration, and were compared to the baseline measurements so as to categorize a patient's LVEF as worsened, unchanged, or improved. Beta-blocker doses were converted to metoprolol equivalent doses based on comparative studies between metoprolol, atenolol, ${ }^{20}$ and carvedilol. ${ }^{21}$ Claims for ED visits and hospitalizations were examined to determine the presence of HF- and COPD-related diagnoses recorded during the ED visit/hospitalization.

Patient characteristics were reported as means with standard deviations for interval- and ratio-level variables and percentages for nominal- and ordinallevel variables. Baseline characteristics and primary and secondary outcomes between cases and controls were compared using conditional logistic regression with adjustment for the matching variables (baseline LVEF, gender, and age). Multivariate outcome analyses included adjustments for the matching variables and characteristics with between-group differences that achieved a $p<0.2$ in the univariate analyses (i.e., NYHA class, hypertension status). Multivariate analysis of the hospitalization/ED visit outcome included adjustments for the matching variables, NYHA class, hypertension status, and baseline hospitalization/ED utilization. To ascertain if COPD patients without baseline spirometry were possibly misclassified and, thus, impacted the results, sensitivity analysis was conducted by removing such patients $(n=26)$ and their matched controls $(n=41)$ and re-performing the outcomes analyses. The alpha was set at 0.05 . Analyses were performed with SAS v9.1.3 (Cary, NC).

\section{RESULTS}

A total of 654 patients were enrolled in the KPCO HF Clinic between September 1, 2001 and September 1, 2003. Patients were excluded from the study for: no beta-blocker initiation or dose titration in the HF clinic $(n=107),<2 \mathrm{HF}$ clinic visits $(n=76)$, or LVEF $>40 \%(n=18)$ (Figure 1$)$. Of the remaining 453 patients, 122 had a COPD diagnosis. However, 33 were excluded because the COPD diagnosis was not confirmed $(n=20)$ or spirometry indicated only reactive airway disease $(n=13)$. Thus, 89 and 331 patients with and without COPD, respectively, were available for matching, and 86 COPD patients were matched to 137 patients without COPD. 


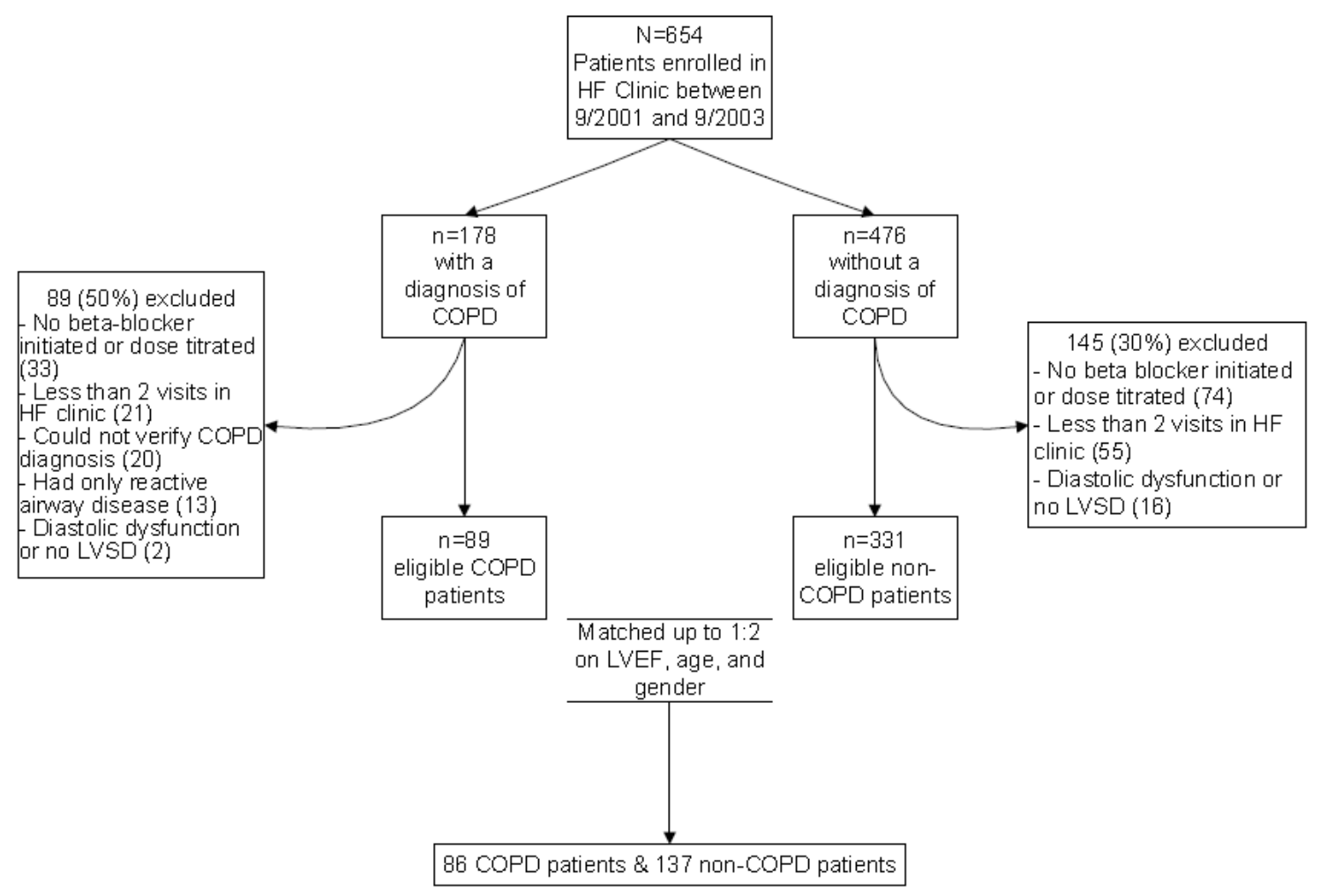

Figure 1: Patient Dispositions

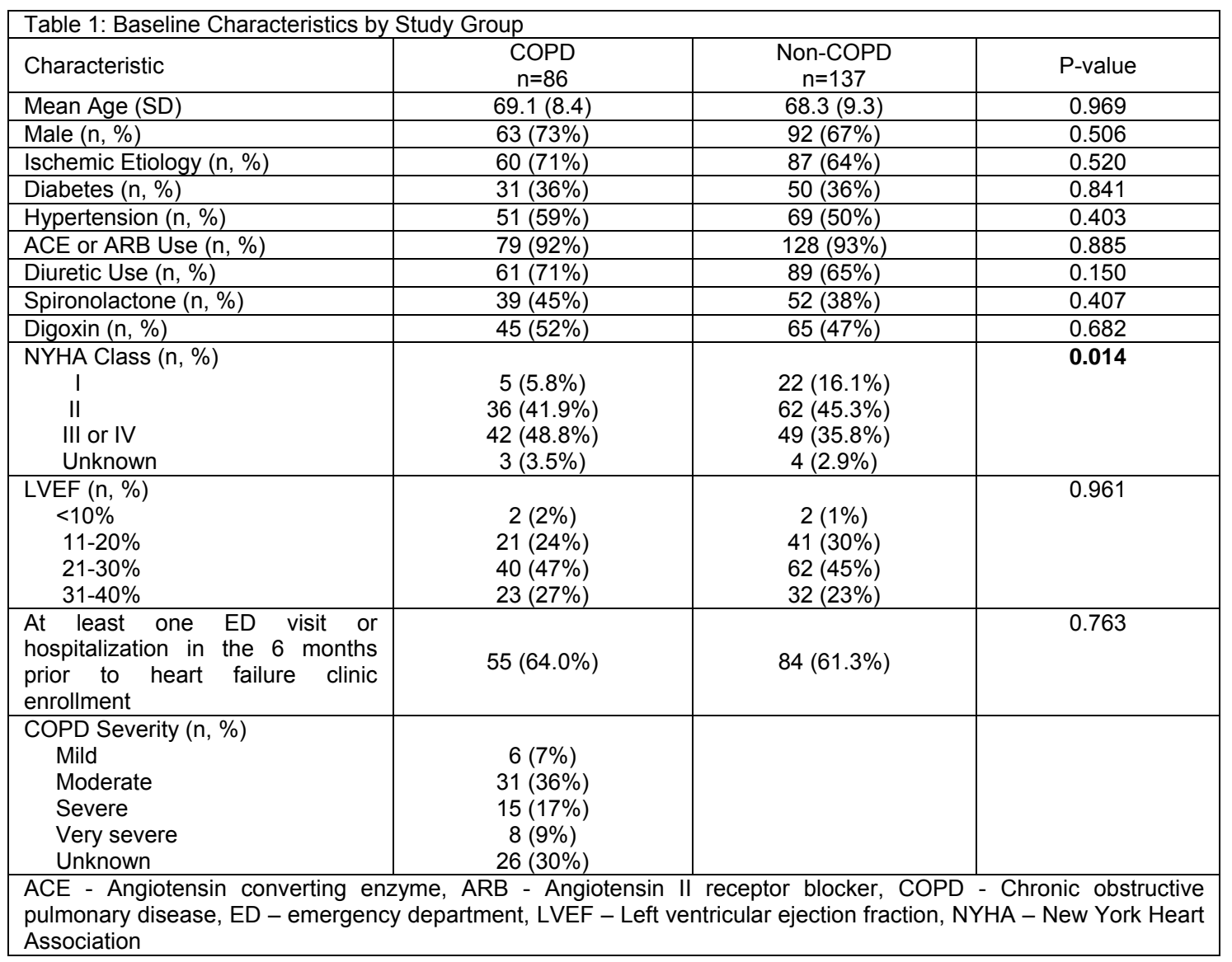




\begin{tabular}{|c|c|c|c|c|}
\hline & $\begin{array}{c}\text { COPD } \\
n=86\end{array}$ & $\begin{array}{c}\text { Non-COPD } \\
n=137\end{array}$ & P-value ${ }^{1}$ & Adjusted P-value ${ }^{2}$ \\
\hline Beta-blocker persistence & $81(94.2 \%)$ & $128(93.4 \%)$ & 0.463 & 0.842 \\
\hline \multicolumn{5}{|l|}{ Beta-blocker agent } \\
\hline Metoprolol & $75(87.2 \%)$ & $111(81.0 \%)$ & 0.208 & 0.228 \\
\hline Atenolol & $4(4.7 \%)$ & $6(4.4 \%)$ & 0.803 & 0.793 \\
\hline Carvedilol & $2(2.3 \%)$ & $11(8.0 \%)$ & 0.227 & 0.435 \\
\hline None & $5(5.8 \%)$ & $9(6.6 \%)$ & 0.463 & 0.842 \\
\hline $\begin{array}{l}\text { Achieved } \geq 100 \mathrm{mg} / \text { day of metoprolol } \\
\text { equivalent dose }\end{array}$ & $44(51.2 \%)$ & $88(64.2 \%)$ & 0.163 & 0.188 \\
\hline $\begin{array}{l}\text { LVEF category change among those } \\
\text { patients with both a baseline and } \\
\text { follow-up measure } \\
\text { Worsened } \\
\text { Unchanged } \\
\text { Improved }\end{array}$ & $\begin{aligned} n=50 \\
5(10.0 \%) \\
7(14.0 \%) \\
38(76.0 \%)\end{aligned}$ & $\begin{aligned} & n=73 \\
& 6(8.2 \%) \\
& 25(34.2 \%) \\
& 42(57.5 \%) \\
&\end{aligned}$ & $\begin{array}{l}0.585 \\
\mathbf{0 . 0 2 8} \\
\mathbf{0 . 0 1 7}\end{array}$ & $\begin{array}{l}0.449 \\
\mathbf{0 . 0 4 0} \\
\mathbf{0 . 0 2 4} \\
\end{array}$ \\
\hline $\begin{array}{l}\text { Patients with at least one ED visit } \\
\text { OR hospitalization }\end{array}$ & $46(53.5 \%)$ & $66(48.2 \%)$ & 0.202 & $0.169^{3}$ \\
\hline \multicolumn{5}{|c|}{$\begin{array}{l}1 \text { P-values controlling for matching variables (age, sex, baseline ejection fraction). } \\
2 \text { P-values adjusted for matching variables and HTN and baseline NYHA class. } \\
3 \text { P-values adjusted for matching variables, HTN, baseline NYHA class, and baseline hospitalization/ED visit } \\
\text { ED - emergency department, HF - heart failure, HTN - hypertension status, LVEF - Left ventricular ejection fraction, SD } \\
\text { - standard deviation }\end{array}$} \\
\hline
\end{tabular}

\begin{tabular}{|c|c|c|c|}
\hline Therapy & $\begin{array}{l}\mathrm{N}, \% \text { with at least one outpatient } \\
\text { purchase during } 6 \text { months prior to HF } \\
\text { Clinic enrollment }\end{array}$ & $\begin{array}{l}\mathrm{N}, \% \text { with at least one outpatient } \\
\text { purchase during } 6 \text { months after beta- } \\
\text { blocker titration }\end{array}$ & P-value \\
\hline Albuterol & $47(55 \%)$ & $35(41 \%)^{1}$ & 0.023 \\
\hline Ipratropium & $28(33 \%)$ & $22(26 \%)^{2}$ & 0.157 \\
\hline Corticosteroid & $27(31 \%)$ & $15(17 \%)^{3}$ & 0.008 \\
\hline Oxygen & $40(47 \%)$ & $43(50 \%)^{4}$ & 0.250 \\
\hline \multicolumn{4}{|c|}{$\begin{array}{l}127 \text { of } 47(58 \%) \text { patients who were receiving albuterol at baseline were persistent with it in the follow-up period. } \\
216 \text { of } 28(57 \%) \text { patients who were receiving ipratropium at baseline were persistent with it in the follow-up period } \\
312(44 \%) \text { patients who were receiving corticosteroid at baseline were persistent with it in the follow-up period } \\
440(100 \%) \text { patients who were receiving oxygen at baseline }(n=40) \text { were persistent with it in the follow-up period }\end{array}$} \\
\hline
\end{tabular}

Both groups were elderly and predominantly male, had an ischemic HF etiology, and were using an ACE inhibitor or angiotensin II receptor blocker at baseline (Table 1). Patients with COPD were more likely to have a higher (i.e., more severe) NYHA classification compared to the non-COPD cohort $(p=0.014)$. There were no differences between groups in proportion of patients with an ED visit or hospitalization in the six months prior to betablocker initiation. Of the 55 COPD patients with a baseline ED visit/hospitalization, $44 \% \quad(n=24)$ and $35 \%(n=19)$ had at least 1 COPD- and HF-related diagnosis recorded respectively, with that event, including 7 patients with both diagnoses recorded. Of the 84 non-COPD patients with a baseline ED visit/hospitalization, $58 \%(n=49)$ had at least $1 \mathrm{HF}$ related diagnosis recorded.

With adjustment for the matching variables, NYHA class, and hypertension status, the groups did not differ in the percentages of patients persistent with a beta-blocker at the six-month follow-up (adjusted $p=0.842$ ) or in who achieved a total daily metoprolol dose equivalent of at least $100 \mathrm{mg}$ (adjusted $p=0.188$ ) (Table 2). Among COPD patients who did not persist $(n=5)$, their COPD severity was rated as "Moderate" $(n=4)$ or and "Unknown" $(n=1)$. Among those patients with both baseline and follow-up measurements $(n=50$ and $n=73$ for COPD and nonCOPD patients, respectively), the majority of patients in both groups demonstrated an improved ejection fraction; however, a higher percent of COPD patients demonstrated improvement $(76 \%$ and $58 \%$ in the COPD and non-COPD groups, respectively; adjusted $p=0.024$ ).

The proportion of patients with at least 1 ED visit or hospitalization in the six-month post-titration period was substantial but similar between the groups (54\% and $48 \%$ for the COPD and non-COPD patients, respectively, adjusted $p=0.169)$. Of the 46 COPD patients with a follow-up ED visit/hospitalization, $40 \% \quad(n=18)$ and $50 \% \quad(n=23)$ had at least 1 COPD- and/or HF-related diagnosis recorded ( 7 of these patients had both a COPDand HF-related diagnosis recorded). Of the 66 nonCOPD patients with a follow-up ED visit/hospitalization, 38\% $(n=25)$ had at least $1 \mathrm{HF}$ related diagnosis recorded in the ED/hospital.

In the sensitivity analysis where COPD patients without baseline spirometry plus their matched controls were removed, similar outcomes were found. There were equivalent proportions of patients persistent with a beta-blocker $(93 \%$ and $94 \%$ of COPD and non-COPD patients, respectively, adjusted $p=0.479$ ), achieving a total daily metoprolol dose equivalent of $>100 \mathrm{mg}(55 \%$ and $65 \%$ of COPD and non-COPD patients, respectively, adjusted $p=0.282$ ), and experiencing a follow-up ED 
visit/hospitalization $(58 \%$ and $47 \%$ of COPD and non-COPD patients, respectively, adjusted $p=0.158)$. Nevertheless, COPD patients were more likely to have had an improvement in their LVEF $(80 \%$ and $58 \%$ of COPD and non-COPD patients, respectively, adjusted $\mathrm{p}=0.031$ ).

Among all COPD patients, utilization of COPD medications did not increase after beta blocker titration was completed compared to before betablocker initiation. Specifically, utilization of albuterol and inhaled corticosteroids actually decreased as evidenced by reductions in the proportion of patients who filled at least one prescription for one of these medications in the follow-up compared to the pre-HF Clinic period ( $55 \%$ to $41 \%, p=0.023$ for albuterol, and $31 \%$ to $17 \% \quad p=0.008$ for inhaled corticosteroids, Table 3). Ipratroprium and oxygen use did not change significantly. Few patients in either group discontinued beta-blocker therapy during the follow-up period $(6 \%$ and $7 \%$ of COPD and non-COPD patients, respectively) (Table 4). The most common reason for discontinuation was bradycardia.

\begin{tabular}{|c|c|c|}
\hline Reason & $\begin{array}{c}\text { COPD } \\
(n=5)\end{array}$ & $\begin{array}{c}\text { Non-COPD } \\
(n=9)\end{array}$ \\
\hline Bradycardia & $2(2.3 \%)$ & $3(2.2 \%)$ \\
\hline Wheezing & 0 & $1(0.7 \%)$ \\
\hline Death & $2(2.3 \%)$ & $1(0.7 \%)$ \\
\hline Hypotension & $1(1.1 \%)$ & $2(1.5 \%)$ \\
\hline Patient refusal & 0 & $1(0.7 \%)$ \\
\hline Hospice entry & 0 & $1(0.7 \%)$ \\
\hline
\end{tabular}

\section{DISCUSSION}

Our study of patients with and without COPD enrolled in a heart failure clinic identified that betablockers were well tolerated in patients with COPD as evidenced by $>90 \%$ persisting with beta-blocker therapy six months after beta blocker initiation or titration. This rate of therapy persistence was similar to HF patients without COPD. Sensitivity analysis confirmed these findings. To the authors' knowledge, this is the largest study of its kind to include LVEF outcomes among COPD patients with left ventricular systolic dysfunction.

Similar success in beta-blocker persistence has been reported in two other studies. A study of a HF clinic in the United Kingdom also found a high rate of beta-blocker persistence in patients with COPD, although the study differed in their primary betablocker choice, which was carvedilol or bisoprolol. ${ }^{14}$ After one year, 109 of 124 COPD patients (88\%) persisted on beta-blocker therapy compared to 206 of 232 non-COPD patients $(89 \% ; \mathrm{p}>0.05) .{ }^{14} \mathrm{~A}$ retrospective study in an outpatient HF clinic included 73 and $113 \mathrm{HF}$ patients with and without COPD. ${ }^{16}$ Of the patients who initiated beta-blocker therapy with carvedilol or bisoprolol, persistence rates at 14 months were $90 \%$ and $91 \%$ in the COPD and non-COPD patients, respectively $(p=0.71)$.
In our study, improved cardiac function was identified in a significantly larger proportion of COPD patients compared to non-COPD patients. Kotlyar and colleagues also reported improvements in cardiac function (left ventricular end-diastolic diameter decreased from $76(S D=11) \mathrm{mm}$ to 72 $(S D=14) \mathrm{mm}, p=0.01$ and left ventricular endsystolic diameter decreased from $65(S D=13) \mathrm{mm}$ to $60(S D=15) \mathrm{mm}, \mathrm{p}=0.01)$ at six month follow-up in their patients with HF and lung disease; however, they did not evaluate a control group of patients without lung disease. ${ }^{18}$

Intuition would dictate that heart failure patients without COPD would be able to achieve higher beta-blocker dose than HF patients with COPD because at higher doses, ( $\geq 100 \mathrm{mg}$ per day) metoprolol is less beta-1 selective and more likely to negatively affect airways. ${ }^{8,9}$ In our matched study, we identified no adjusted difference between HF patients with and without COPD in the mean daily dose achieved or the percent of patients achieving a $\geq 100 \mathrm{mg}$ beta-blocker daily dose. This finding is consistent with two other studies, each reporting that mean daily beta-blocker doses did not differ between patients with and without COPD. ${ }^{14,16}$ However, both of these studies primarily investigated carvedilol and bisoprolol use. The mean carvedilol equivalent dose for all 186 patients included in one study was reported to be $33.6 \mathrm{mg}$ (equivalent to approximately $134 \mathrm{mg}$ of metoprolol), ${ }^{20}$ however, they did not report the mean doses for patients with and without COPD. ${ }^{16}$ This appears to be a moderately higher total daily betablocker dose than the $97.1 \mathrm{mg}$ (COPD patients) and $106.6 \mathrm{mg}$ (non-COPD patients) mean daily doses we achieved and closer to the target dose of 200 $\mathrm{mg}$ daily. Like our study, the authors reported no increased rate of death or all-cause hospitalization between the groups $(44 \%$ in the COPD group and $35 \%$ in the non-COPD group; hazard ratio 1.40 , $95 \% \mathrm{Cl} 0.88-2.24)$.

The small, open-label study by Kotlyar and colleagues evaluated persistence of carvedilol for 6 months in $31 \mathrm{HF}$ patients with COPD. ${ }^{18}$ While $84 \%$ of patients were persistent at 6 months, a small proportion $(n=5)$ discontinued therapy. The reasons for discontinuation identified included wheezing $(n=1)$, worsening HF $(n=3)$, and bradycardia $(n=1){ }^{18}$ In our study, bradycardia was the cause of betablocker discontinuation in $2 \%$ of patients with and without COPD. Bradycardia is most likely not related to COPD but a result of known beta-blocker pharmacodynamic effects. ${ }^{1}$

Our study is not without limitations. As is inherent with a retrospective study, some data were missing or incomplete. Spirometry data and ejection fraction information were not available for all patients at baseline and follow-up. Nevertheless, we were able to assess the change in ejection fraction in a majority of patients as the majority of patients in both groups had baseline and follow-up ejection fractions. Our sample size was restricted to patients treated in our clinic; thus, we had limited power to assess differences in clinical outcomes. A retrospective power calculation revealed we had 
only $5 \%$ power to detect a difference in beta-blocker persistence $(94.2 \%$ vs. $93.4 \%$ ) and $13 \%$ power to detect the difference in follow-up ED visits and hospitalizations $(53.5 \%$ vs. $48.2 \%)$. While seemingly low power, these differences (particularly in persistence) do not appear to have clinical significance.

\section{CONCLUSIONS}

This study provides additional evidence that betablockers can be used successfully in patients with COPD without reactive airway disease when indicated for a cardiac condition, such as heart failure, without increasing the risk of hospitalization or ED visit. In addition, there is potential to improve cardiac function in HF patients with COPD with the use of beta-blockers. Our results, in conjunction with other studies, support the use of beta-blockers in the population of heart failure patients with COPD. However, a larger prospective study with sufficient power is needed to confirm this.

\section{CONFLICT OF INTEREST}

The authors have no conflicts of interest including, but not limited to, consulting fees, paid expert testimony, employment, grants, honoraria, patents, royalties, stocks, or other financial or material gain that may involve the subject matter of the manuscript.

This investigation was fully funded by the Kaiser Permanente Colorado Pharmacy Department.

\section{References}

1. Writing Committee to update the 2001 Guidelines for the evaluation and management of heart failure chaired by Hunt SA. ACC/AHA 2005 guideline update for the diagnosis and management of chronic heart failure in the adult: A report of the American College of Cardiology/American Heart Association task force on practice guidelines. American College of Cardiology Web Site available at: http://content.onlinejacc.org/cgi/reprint/46/6/e1.pdf (accessed 19 February 2009).

2. Heart Failure Society of America Writing Committee Co-Chaired by Adams, KF and Lindenfeld J. HFSA 2006 Comprehensive Heart Failure Practice Guideline. J Card Fail. 2006;12:e1-e119. doi:10.1016/j.cardfail.2005.12.001

3. Brophy JM, Joseph L, Rouleau JL. Beta-Blockers in Congestive Heart Failure. A bayesian meta-analysis. Ann Intern Med. 2001;134:550-560.

4. The MERIT-HF Study Group. Effects of controlled-release metoprolol on total mortality, hospitalizations, and well-being in patients with heart failure: the metoprolol CR/XL randomized intervention trial in congestive heart failure (MERIT-HF). JAMA. 2000;283:1295-1337. doi:10.1001/jama.283.10.1295

5. The MERIT-HF Study Group. Effect of metoprolol CR/XL in chronic heart failure: metoprolol CR/XL randomised intervention trial in congestive heart failure (MERIT-HF). Lancet. 1999;353:2001-2007. doi:10.1016/S01406736(99)04440-2

6. CIBIS II Investigators and Committees. The cardiac insufficiency bisoprolol study II (CIBIS II): a randomized trial. Lancet. 1999;353:9-13. doi:10.1016/S0140-6736(98)11181-11189

7. Sinha S, Goldstein M, Penrod J, Hochman T, Kamran M, Tenner C, Cohen G, Schwartz MD. Brief report: beta-blocker use among veterans with systolic heart failure. J Gen Intern Med. 2006;21:1306-1309. doi:10.1111/j.15251497.2006.00601.x

8. Dart RA, Gollub S, Lazar J, Nair C, Schroeder D, Woolf SH. Treatment of systemic hypertension in patients with pulmonary disease: COPD and asthma. Chest. 2003;123:222-243. doi:10.1378/chest.123.1.222

9. Gheorghiade M, Goldstein S. Beta-blockers in the post-myocardial infarction patient. Circulation .2002;106:394-398. doi:10.1161/01.CIR.0000019582.39797.EF

10. Sirak, TE, Jelic S, LeJemtel TH. Therapeutic update: non-selective beta- and alpha-adrenergic blockade in patients with coexistent chronic obstructive pulmonary disease and chronic heart failure. J Am Coll Cardiol. 2004;44(3):497-502. doi:10.1016/j.jacc.2004.03.063

11. Le Jemtel TH, Padeletti M, Jelic S. Diagnostic and therapeutic challenges in patients with coexistent chronic obstructive pulmonary disease and chronic heart failure. J Am Coll Cardiol. 2007;49;171-180. doi:10.1016/j.jacc.2006.08.046

12. van der Woude HJ, Zaagsma J, Postma DS, Winter TH, van Hulst M, Aalbers R. Detrimental effects of beta-blockers in COPD: a concern for nonselective beta-blockers. Chest. 2005;127:818-824. doi :10.1378/chest.127.3.818

13. Egred $M$, Shaw $S$, Mohammad $B$, Waitt $P$, Rodrigues $E$. Under-use of beta-blockers in patients with ischaemic heart disease and concomitant chronic obstructive pulmonary disease. Q J Med. 2005;98:493-497. doi:10.1093/qjmed/hci080

14. Shelton RJ, Rigby AS, Clelan JGF, Clark AL. Effect of a community heart failure clinic on uptake of beta-blockers by patients with obstructive airways disease and heart failure. Heart. 2006;92:331-336. doi:10.1136/hrt.2004.059758

15. Fogari R, Zoppi A, Tettamanti F, Poletti L, Rizzardi G, Fiocchi G. Comparative effects of celiprolol, propranolol, oxprenolol, and atenolol on respiratory function in hypertensive patients with chronic obstructive lung disease. Cardiovasc Drugs Ther. 1990;4:1145-1149. doi:10.1007/BF01856511

16. Mascarenhas J, Lourenco $P$, Lopes $R$, Bettencourt $P$. Chronic obstructive pulmonary disease in heart failure: prevalence, therapeutic and prognostic implications. Am Heart J. 2008;155:521-525. doi:10.1016/j.ahj.2007.10.040

17. Salpeter S, Ormiston t, Salpeter E. Cardioselective beta-blockers for chronic obstructive pulmonary disease. Cochrane Database Syst Rev. 2005 Oct 19;(4):CD003566. doi:10.1002/14651858.CD003566.pub2

18. Kotlyar E, Keogh AM, Macdonald PS, Arnold RH, McCaffrey DJ, Glanville AR. Tolerability of carvedilol in patients with heart failure and concomitant chronic obstructive pulmonary disease or asthma. J Heart Lung Transplant. 2002;21(12):1290-1295. doi:10.1016/S1053-2498(02)00459-X

19. GOLD Executive and Science Committees. Global Strategy for the Diagnosis, Management and Prevention of COPD, Global Initiative for Chronic Obstructive Lung Disease (GOLD) 2007. Available at: http://www.goldcopd.org/Guidelineitem.asp?l1=2\&l2=1\&intld=2003 (accessed 19 February 2009). 
20. Haley RJ, Licht JH: Metoprolol, atenolol, and propranolol: a comparison at equivalent doses in the treatment of hypertension. Curr Ther Res Clin Exp. 1984;36:993-1003.

21. van der Does R, Hauf-Zachariou U, Pfarr E, Holtbrüugge W, König S, Griffiths M and Lahiri A. Comparison of safety and efficacy of carvedilol and metoprolol in stable angina pectoris. Am J Cardiol. 1999;83:643-649. doi:10.1016/S00029149(98)00960-6

Welcome to the $16^{\text {th }}$ ISPW!

Welcome to Lisboa!
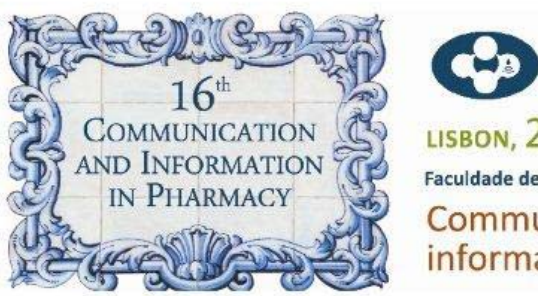

LISBON, 23rd $/ 26^{\text {th }}$ AUGUST 2010 Faculdade de Farmácia da Universidade de Lisboa Communication and information in pharmacy

This is a preliminary short announcement for the $16^{\text {th }}$ ISPW

Host Institution and Venue

Faculty of Pharmacy, University of Lisbon, Portugal

Dates

$23^{\text {rd }}$ to $26^{\text {th }}$ August 2010

Key note Speakers and further information soon to be announced at www.ff.ul.pt/16ISPW

For any inquiries, please use the following email address: 16 ISPW@ff.ul.pt

Hope to have you here in Summer 2010! 